\title{
HISTÓRICO DE VIOLÊNCIA CONTRA MULHER E FEMINICÍDIO
}

\author{
HISTORY OF VIOLENCE AGAINST WOMEN AND FEMINICIDE
}

\author{
Tiago dos Santos Arão ${ }^{1}$ \\ Leandro Luis de Lima² \\ Carlos Eduardo Silva Abbadie ${ }^{3}$ \\ Bruno de Castro Lino ${ }^{4}$ \\ Leonardo Mattos 5
}

RESUMO: O presente artigo tem como objeto de estudo o feminicídio. Tal crime foi introduzido no ordenamento jurídico brasileiro, notadamente no Código Penal, pela lei 13.104/2015. Antes da referida lei, não havia nenhuma punição especial para o homicídio contra a mulher por razões de gênero. $O$ feminicídio era punido de forma genérica, como sendo o homicídio no artigo I2I do Código Penal. $\mathrm{O}$ objetivo do artigo é ampliar o conhecimento a respeito deste tema e estabelecer um debate a respeito desse crime com altos índices de ocorrência. A justificativa para a escolha do tema em questão reside na importância de aprimorar os conhecimentos sobre o assunto, que se encontra em voga, por meio de pesquisa e exposição de ideias. Para tanto, adentrando aos procedimentos metodológicos, no que se refere à abordagem, trata-se de uma pesquisa com abordagem qualitativa. $O$ tipo de pesquisa é a bibliográfica. O método utilizado é o dedutivo.

PALAVRAS-CHAVE: Feminicídio. Mulher. Crime.

ABSTRACT: The purpose of this article is to study feminicide. Such a crime was dependent on the Brazilian legal system, notably on the Penal Code, by law 13.104/2015. Before the law, there was no special punishment for homicide against women for gender reasons. Femicide was punished in a generic way, as homicide in Article I2I of the Penal Code. The aim of the article is to expand knowledge about

\footnotetext{
${ }^{\text {I }}$ Formado em Letras pela UFPel-RS; Especialista em Inteligência Policial, Segurança Pública e Direitos Humanos. Policial Penal do Estado do Rio Grande do Sul (SUSEPE - RS).E-mail: tiago-arao@susepe.rs.gov.br.

${ }^{2}$ Formado em Segurança Pública pela Ulbra-Canoas-RS. Especialista em Direito Criminal. Policial Penal do Estado do Rio Grande do Sul (SUSEPE - RS). E-mail: leandro-luis@susepe.rs.gov.br.

${ }^{3}$ Formado em Direito pela URI-Santiago-RS. Especialista em Segurança Pública. Policial Penal do Estado do Rio Grande do Sul (SUSEPE - RS).E-mail: carlos-abbadie@susepe.rs.gov.br.

${ }_{4}$ Mestre em Comunicação Social pela UFSM-RS. Especialista em Direitos Humanos e Ressocialização. Policial Penal do Estado do Rio Grande do Sul (SUSEPE - RS).E-mail: bruno-lino@susepe.rs.gov.br.

5 Especialista em Segurança Pública, Gestão Prisional e Inteligência Policial. Policial Penal do Estado do Rio Grande do Sul (SUSEPE - RS).E-mail: leonardo-mattos@susepe.rs.gov.br.
} 
this topic and establish a debate about crime with high rates of occurrence. A justification for choosing the topic in question lies in the importance of improving knowledge on the subject, which is in vogue, through research and exposure of ideas. For that, entering the methodological procedures, with regard to the approach, it is a research with a qualitative approach. The type of research is bibliographic. The deductive method is used.

KEYWORDS: Feminicide. Women. Crime.

\section{INTRODUÇÃO}

A violência praticada contra a mulher não é observada somente na atualidade, ela é praticada há muitas gerações, e, por mais de séculos, as mulheres vêm sendo agredidas e mortas das mais diversas formas. Como, por exemplo, durante os séculos XVI e XVII, época na qual muitas delas foram torturadas e queimadas vivas sob a alegação de serem bruxas.

A violência doméstica contra a mulher constitui uma problemática que atinge toda a população feminina independente de classe social, raça ou etnia, ou seja, é um fenômeno universal.

Os valores adquiridos do sistema patriarcal continuam sendo reproduzidos e ainda reconfigurados de acordo com o momento histórico em que se inserem.

$\mathrm{Na}$ obra "Violência contra a mulher: O homicídio privilegiado e a violência doméstica", o autor Paulo Marco Ferreira Lima (2009) diz que a violência contra a mulher seria uma forma de manifestar o domínio entre homem e mulher, dizendo também que ela ocorre por fatores culturais e por várias mudanças de padrões da sociedade. Ou seja, os mais fortes utilizavam-se da força para obrigar os mais frágeis a realizar as suas vontades ou até mesmo, era utilizada por questão de segurança, com a intenção do homem proteger a mulher.

O feminicídio representa a última etapa de um ciclo de violência que leva ao último ato: a morte. Trata-se de crimes cometidos por homens contra as mulheres e suas motivações são as mais diversas, precedido por outros eventos, tais como agressões físicas e psicológicas com o objetivo de submeter as mulheres a uma lógica de dominação masculina baseado em um padrão cultural que subordina a mulher.

Desta forma, o artigo se desenvolve a estudar a discriminação histórica da mulher, a origem do termo feminicídio, a sua conceituação, conforme o entendimento de diversos autores e a inserção desse crime no Código Penal. 


\section{MULHER: DISCRIMINAÇÃO HISTÓRICA E PRECONCEITO}

Durante anos, a sociedade construiu em torno de si, com o uso do senso comum, um estereótipo relacionado ao sexo feminino, o que se tornou o primeiro passo para a construção das bases do preconceito e da discriminação.

O termo gênero, então, é utilizado para: demonstrar e sistematizar as desigualdades socioculturais existentes entre mulheres e homens, que repercutem na esfera da vida pública e privada de ambos os sexos, impondo a eles papéis sociais diferenciados que foram construídos historicamente e criaram polos de dominação e submissão. Impõe-se o poder masculino em detrimento dos direitos das mulheres, subordinando-as às necessidades pessoais e políticas dos homens, tornando-as dependentes. (TELES e MELO, 2003, p.16)

Segundo Simone de Beauvoir, não se nasce mulher, mas se torna mulher ao se aprender comportamentos, formas de pensar e de agir em função do gênero. (BEAUVOIR, 1990).

Quando Simone de Beauvoir diz que a mulher se torna mulher, ela fala de um processo que é moldado por uma violência oculta. Uma violência que se apresenta sob a forma de mitificação do "universo feminino", da "feminilidade" e do "maternal". Uma violência que se esconde sob palavras bonitas como "altruísmo”, "generosidade”, "sinceridade”, “dedicação”, “docilidade”, "passividade” e tantas outras que, ao mesmo tempo em que escondem, naturalizam a violência contra a mulher. Uma violência que aprisiona a mulher na condição de "carinhosa”, "amorosa'. (BEAUVOIR, 1990).

A discriminação contra a mulher é uma realidade há muito verificada, pois suas raízes remontam à Antiguidade.

O Código hindu de Manu estabelecia: A mulher, durante a sua infância, depende de seu pai, durante a mocidade, de seu marido, em morrendo o marido, de seus filhos, se não tem filhos, dos parentes próximos de seu marido, porque a mulher nunca deve governar-se à sua vontade. (STREY, 1997, p. 24)

Ao pretender abordar as origens da submissão da mulher, torna-se imprescindível compreender quem é o seu opressor, que é a sociedade de classes, que tem no homem o agente dessa opressão.

Ainda, tal opressão somente poderia ser resolvida com o rompimento da ordem econômica vigente, luta essa que só pode ser travada com o enfrentamento do capital, ou seja, com os fatores decisivos (crenças, valores, cultura) que determinaram a superestrutura ideológica de sustentação dessa submissão. 
No império romano, a mulher levava o título de "rés", ou seja, coisa. Para mostrar o seu autoritarismo, o homem usava da violência para com a mulher, atitude esta que era comum naquela época, não gerando nenhum tipo de reprovação perante a sociedade.

O próprio Direito Romano já retirava da mulher de capacidade jurídica. Por sua vez a religião era prerrogativa masculina da qual a mulher somente poderia participar com a breve autorização do pai ou marido.

$\mathrm{Na}$ Grécia Antiga havia muitas diferenças entre homens e mulheres. As mulheres não tinham direitos jurídicos, não recebiam educação formal, eram proibidas de aparecer em público sozinhas, sendo confinadas em suas próprias casas em um aposento particular, enquanto aos homens, estes e muitos outros direitos eram permitidos, como Vrissimtzis (2002, p. 38) elucida:

[...] o homem era polígamo e o soberano inquestionável na sociedade patriarcal, a qual pode ser descrita como o 'clube masculino mais exclusivista de todos os tempos'. Não apenas gozava de todos os direitos civis e políticos, como também tinha poder absoluto sobre a mulher.

Como se demonstrou, a mulher era vista somente como um objeto, era inferiorizada, surgindo desse tratamento a violência "facilitada", que perdura até hoje, tendo sido necessária a criação de leis para inibir essa violência, conforme será visto a seguir.

\section{A ORIGEM DO TERMO FEMINICÍDIO}

O termo feminicídio apareceu pela primeira vez no livro A SatiricalViewof London, de John Corry (I8or), no qual o historiador mencionou o assassinato de uma mulher, entretanto, apenas dois séculos seguintes essa expressão teria seu conteúdo utilizado novamente.

Já no ano de 1976, a palavra feminicídio foi utilizada pela pesquisadora americana cujo nome era Diana Russell. A autora citou o termo em um discurso perante o Tribunal Internacional de Crimes contra Mulheres, realizado na cidade de Bruxelas na Bélgica. Alguns doutrinadores entendem que com Russel, o termo foi utilizado pela primeira vez.

Diana Russell utilizou a palavra feminicídio, dentro de um contexto de assassinatos de mulheres como crime de guerra. Esse encontro reuniu mais de duas mil mulheres de 40 Países, para trocar experiências, sobre a violência feminina que ocorria na época e com a denúncia de abusos cometidos 
contra elas. Nessa época, Diana Russell utilizou a expressão para se referir tão somente aos assassinatos de mulheres, praticada por homens.

Em 1992, o termo é ampliado, de modo a designar as mortes de mulheres pelo fato de serem mulheres. Em sua obra, as autoras supracitadas descrevem que para se classificar uma morte como feminicídio, esta deveria resultar de uma discriminação de gênero, bem como tratar-se do ponto final de um processo contínuo de violência, abusos e privações, as quais, a vítima enquanto mulher, esteve submetida ao longo de sua vida.

A partir de então, esse termo foi largamente utilizado, tendo em vista um caso específico no México, na cidade de Juarez. Nesse local, ocorria violência generalizada contra as mulheres, estupros, desaparecimento e morte, tais crimes restavam impunes dentro daquela cultura, chegando, inclusive, a ter uma condenação pela Corte Interamericana de Direitos Humanos, no que ficou conhecido como o caso do Algodonero.

\section{CONCEITUAÇÃO}

Aqui, a primeira questão a ser levantada é como se definem os feminicídios. É um mote de suma importância, primeiro porque é um tema pouco conhecido dentro da própria academia e do direito, quiçá pela população que não tem contato com o assunto. No entanto, a compreensão começa a ser modificada, ao menos no território brasileiro, isso se deve a inclusão do feminicídio no Código Penal.

Sanches (2017, p. 64) entende que::

O feminicídio, entendido como a morte de mulher em razão da condição em sido sexo feminino. A incidência da qualificadora reclama situações de violência praticada contra a mulher, em contexto caracterizado por relação de poder e submissão, praticada por homem ou mulher sobre mulher em situação de vulnerabilidade.

Para Fragoso (2002), o feminicídio diz respeito a atos contínuos de violência, nas quais resultam em danos emocionais, psicológicos, agressões, torturas, estupro, prostituição, assédio sexual, abuso infantil, infanticídio de meninas, mutilações genitais, violência doméstica, e qualquer ação que gera a morte de mulher sem que o Estado atue na punição. Reflete sobre variabilidade do gênero e de poder, considerando o contexto, social, político e econômico, bem como as diferentes formas de ser mulher.

A necessidade em criar uma lei específica no Brasil, que possa prevenir e punir o feminicídio segue orientações de organizações internacionais, tais como a Comissão sobre a situação da Mulher (CSW) e 
o Comitê sobre a Eliminação de todas as Formas de Discriminação contra a Mulher (CEDAW), todos os dois da ONU.

A inclusão da tipificação do feminicídio foi muito solicitada pelos movimentos feministas, ativistas, de certo ponto também para responsabilizar e fomentar a responsabilidade do Estado.

De acordo com Segato (2006, p. II4):

Feminicídio é algo que vai além da misoginia, criando um clima de terror que gera a perseguição e morte da mulher, a partir de agressões físicas e psicológicas dos mais variados tipos, como abuso físico e verbal, estupro, tortura, escravidão sexual, espancamentos, assédio sexual, mutilação genital e cirurgias ginecológicas desnecessárias, proibição do aborto e da contracepção, cirurgias cosméticas, negação da alimentação, maternidade, heterossexualidade e esterilização forçadas.

Nas palavras de Rogério Sanches Cunha (2006):.

Feminicídio, comportamento objeto da lei em comento, pressupõe violência baseada no gênero, agressões que tenham como motivação a opressão à mulher. É imprescindível que a conduta do agente esteja motivada pelo menosprezo ou discriminação à condição de mulher da vítima.

O feminicídio se divide em espécies, há o feminicídio íntimo, que ocorre quando existe ou existiu uma relação afetiva da vítima com o homicida. O feminicídio não íntimo é o contrário do anterior, ocorre quando a vítima não possui qualquer relação com o agressor. Por último, há o feminicídio por conexão, que ocorre quando a mulher assassinada se encontrava na "linha de fogo" de um homem que pretendia matar outra mulher. (CUNHA, 2006).

\section{I A TIPIFICAÇÃO DO FEMINICÍDIO NO CODIGO PENAL BRASILEIRO}

A lei do feminicídio antes de entrar em vigor no país, já era questão regulamentada em vários países da América Latina, não sendo o primeiro a tratar da matéria.

O Brasil foi o $16^{\circ}$ país da América Latina a prever o crime de feminicídio, com a alteração do artigo I2I do Código Penal Brasileiro.

O direito à vida está assegurado na constituição no art. $5^{\circ}$ e deve ser protegido pela lei penal. Dessa forma, a vida é bem jurídico protegido e objeto jurídico do crime de feminicídio, sendo a sua tutela efetivada através da utilização do aparato penal, que objetiva punir quem mata outrem, neste caso, em razão da condição de mulher. 
Decorrente do Projeto de Lei do Senado no 8.305, de 17 de dezembro de 2014, em 9 de março de 2015 foi publicada a Lei no 13.104, alterando o artigo 121 do Código Penal, criando-se uma modalidade de homicídio qualificado, que passou a ser denominado de "feminicídio".

O referido texto legal promoveu ainda a alteração no artigo $\mathrm{I}^{\circ}$, inciso I, da Lei $\mathrm{n}^{\circ}$ 8.072, de 25 de julho de 1990, que trata dos crimes hediondos, incluindo o feminicídio em seu rol.

Com essa mudança, o artigo I2I do Código Penal passou a ter a seguinte redação::

Art. 121. Matar alguém: Pena - reclusão, de seis a vinte anos. [...] Feminicídio VI contra a mulher por razões da condição de sexo feminino: [...] Pena - reclusão, de doze a trinta anos. [...] \& 2o-A Considera-se que há razões de condição de sexo feminino quando o crime envolve: (Incluído pela Lei no 13.104, de 2015) I - violência doméstica e familiar; (Incluído pela Lei no 13.104, de 2015) II - menosprezo ou discriminação à condição de mulher. (BRASIL, 1940).

Silva (2015, p. or) traz em seu artigo, um entendimento acerca da necessidade da tipificação desse crime, aduzindo que a Lei Maria da Penha não se fez eficaz para diminuir a violência contra a mulher:

[...] a Lei Maria da Penha não foi capaz de dissuadir a prática de violência contra a mulher, o que levou o Governo brasileiro a criar uma nova lei com tal propósito. $\mathrm{O}$ Governo não se interessou em estruturar a administração pública para realmente proteger as mulheres, tampouco realizou um diagnóstico com as falhas na concretização das medidas propostas através da referida lei e de Programas de Proteção para uma readequação de ações. Preferiu editar mais uma lei, com um nome de impacto - feminicídio, para, diante de uma realidade de violência contra as mulheres, demonstrar que está à procura de soluções, mesmo que as medidas colocadas em pauta não resultem na efetividade esperada.”.

Consoante a sua importância, é perceptível que a lei foi uma valorosa medida no intuito protetivo, contribuindo inclusive na ampla divulgação do complexo problema que afeta grande parte das mulheres brasileiras, até então, uma violência distante dos olhares da sociedade.

Consoante a sua importância, é perceptível que a lei foi uma valorosa medida no intuito protetivo, contribuindo inclusive na ampla divulgação do complexo problema que afeta grande parte das mulheres brasileiras, até então, uma violência distante dos olhares da sociedade.

À medida que o Estado se mostra inoperante, ou melhor, ineficiente para conter a escala de crescimento do crime organizado, a luta por cidadania e por direitos humanos parece mais difícil e inatingível. O clima de terror provocado pela ação violenta dos criminosos inibe o cidadão de bem, de contribuir no esclarecimento do crime. Por isso se faz necessário que o Estado ofereça segurança e estimulo para que as 
vitimas e testemunhas sintam-se encorajadas para denunciar e testemunhar contra o autor do crime”.

Mapa I: Ranking da violência contra a mulher no mundo

\section{Ranking da violência contra mulher no mundo}

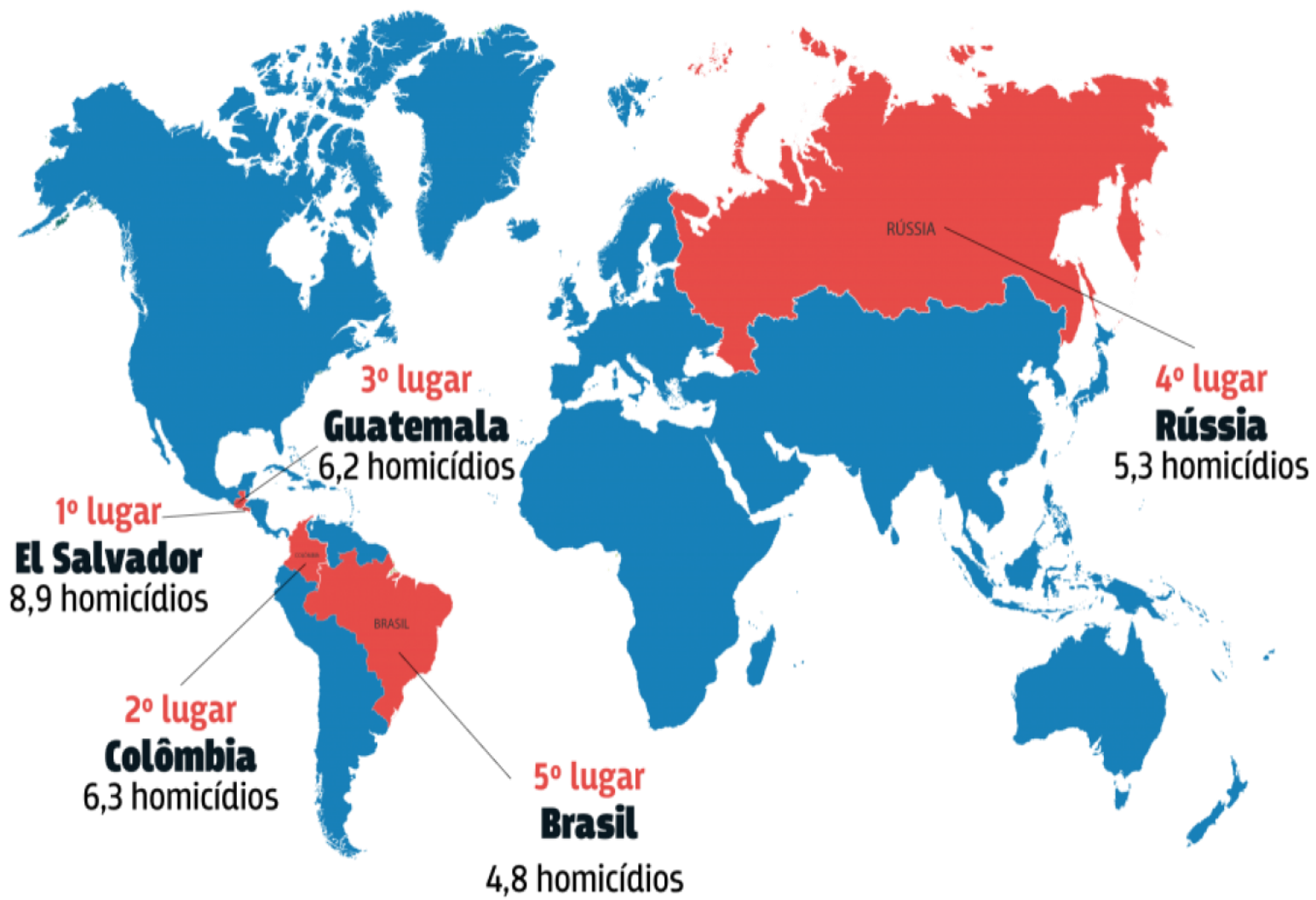

(Taxa de homicídios por 100 mil mulheres)

Fonte: https://nacoesunidas.org/ 


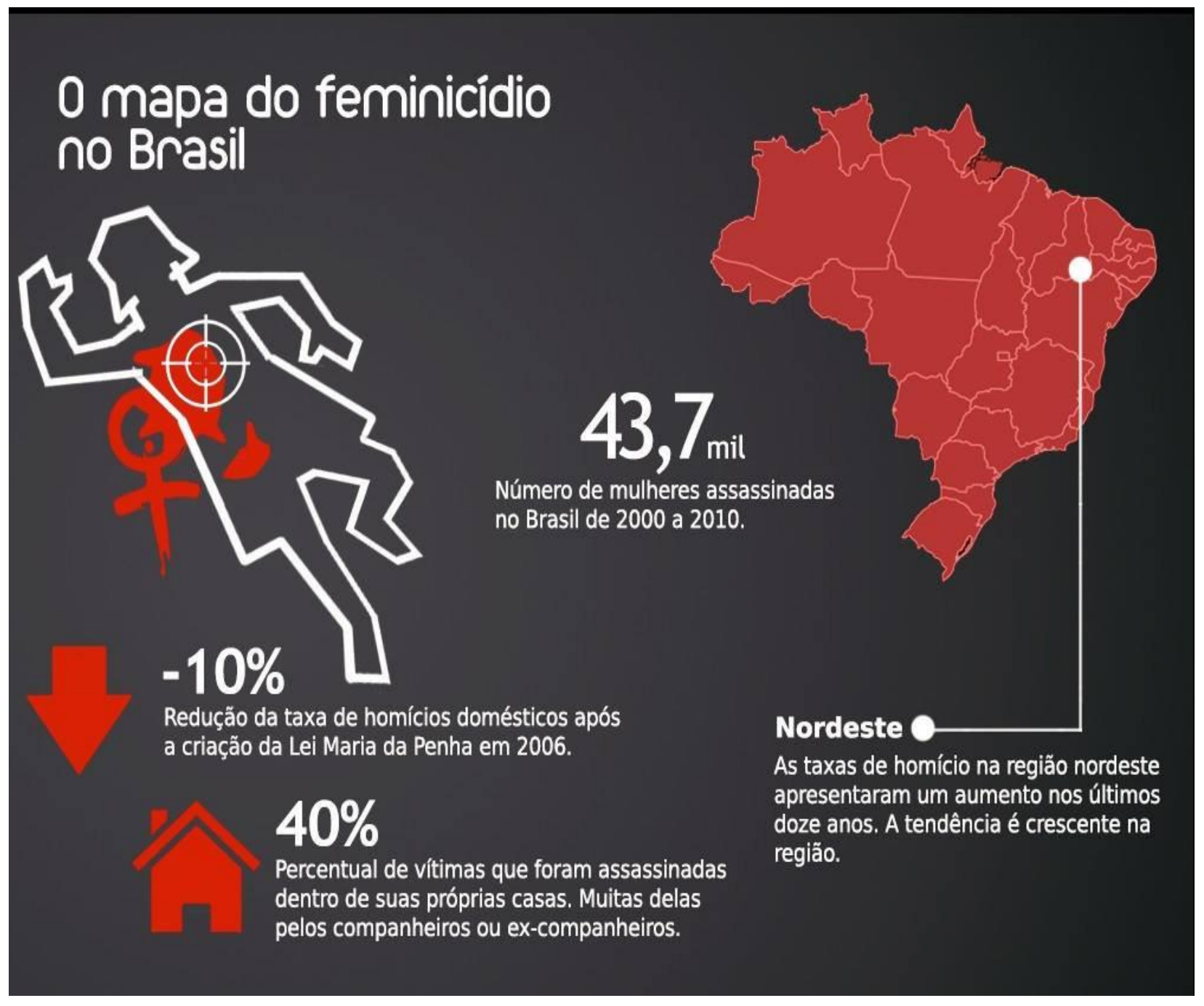

Fonte: https://medium.com/@biafortunato/casos-de-feminic\%C3\%ADdio-aumentam-no-brasil2733487 ibiza

\section{CONCLUSÃO}

Conforme foi estudado no transcorrer deste artigo, a violência contra a mulher ocorre ao longo da história nas mais diversas formas, essa violência se funda em valores patriarcais e machistas que refletem no meio social a exploração e subjugação da mulher. 
É muito claro que, ao editar a nova lei do feminicídio, o poder legislativo objetivou responder às reivindicações de grupos adeptos a defesa aos direitos fundamentais da mulher, valendo-se, para isso, do aumento do rigor repressivo sobre esse tipo de crime.

O propósito do legislativo foi, claramente, enviar uma mensagem a sociedade, com o objetivo de motivar seus membros a respeitarem os ditames da norma, reduzindo esse crime tão terrível.

Em face da luta por justiça de gênero, a criminalização do feminicídio, para além de um caráter simbólico das normas jurídicas, é importante como um dos meios para garantir a efetivação da igualdade entre as pessoas e da dignidade humana.

Desta forma, a especialização da legislação resulta em uma luta pela erradicação da violência e na inserção do feminicídio como uma política de Estado, pois a morte de mulheres, decorrente da discriminação e violência de gênero, ultraja a consolidação dos direitos humanos.

Neste sentido, ressalta-se que o presente artigo não objetivou esgotar o assunto, muito pelo contrário, é uma forma de abordar os pontos principais do assunto e incentivar novas discussões sobre o feminicídio.

\section{REFERÊNCIAS}

BEAUVOIR, Simone. O segundo sexo: a experiência vivida. Rio de Janeiro: Nova Fronteira, I99o.

BIANCHINE, Alice; GOMES, Luiz Flávio. Feminicídio: entenda as questões controvertidas da Lei 13.104/2015. Disponível em: 〈https://professorlfg.jusbrasil.com.br/artigos/173139525/feminicidioentenda-as-questoes-controvertidas-da-lei-13104-2015>. Acesso em: I2 jun. 2020.

BRASIL, Código Penal. Disponível em: 〈http://www.planalto.gov.br/ccivil_03/DecretoLei/Del2848.htm>. Acesso em I2 Jun. 2020.

CUNHA, Rogério Sanches. Manual de Direito Penal Parte Especial. Io. Ed. Juspodvim, 2017.

CUNHA, Rogério Sanches. Violência Doméstica: Lei Maria da Penha (Lei Ir.340/2006). 3. Ed. São Paulo: Editora Revista dos Tribunais, 2orr. 
FRAGOSO, J. M. Feminicídio sexual serial en Ciudad Juárez. 1993-2001. Debate Feminista, ano 13, v. 25. México-DF,2002.

LIMA, Paulo Marco Ferreira. Violência Contra a Mulher. O homicídio privilegiado e a violência doméstica. Editora Atlas, São Paulo. 2009.

SEGATO. Rita Laura. ¿Qué es un feminicidio? Notas para un debate emergente. Série Antropologia no 40I, UNB, Brasília, 2006.

SILVA, Wellyngton Marcos de Ataide. A proteção das mulheres muito além da Lei do Feminicídio. Disponível em: http://www.conteudojuridico.com.br/artigo,a-protecao-das-mulheres-muito-alem-dalei-do-feminicidio,53935.html. Acesso em: 02 jun. 2020.

STREY, Marlene Neves (Org.). Mulher: estudos de gênero. São Leopoldo: Unisinos, 1997.

TELES, Maria Amélia de Almeida; MELO, Mônica de. O que é violência contra a mulher. São Paulo: Brasiliense, 2002.

VARGAS, Elizabeth Castillo. Feminicido. Mujeres que mueren por violência intrafamiliar em Colômbia. Estudio de caso en cinco ciudades del pais. Pro Familia Social - IPPS, Novembro 2007.

VRISSIMTZIS, Nikos A. Amor, Sexo e Casamento na Grécia Antiga. Trad. Luiz Alberto Machado Cabral. I. ed. São Paulo: Odysseus, 2002. 